\title{
Mechanisms of Moral Responsibility: Rethinking Technologies for Domestic Violence Prevention Work
}

\author{
Rosanna Bellini \\ Open Lab, Newcastle University, \\ Newcastle upon Tyne, UK \\ r.f.bellini@newcastle.ac.uk \\ Nicole Westmarland \\ School of Sociology, Durham University \\ Durham, UK \\ nicole.westmarland@durham.ac.uk
}

\author{
Simon Forrest \\ Institute of Health and Society Newcastle University \\ Newcastle upon Tyne, UK \\ Simon.Forrest@newcastle.ac.uk
}

\author{
Jan David Smeddinck \\ Open Lab, Newcastle University, \\ Newcastle upon Tyne, UK \\ Jan.Smeddinck@newcastle.ac.uk
}

\begin{abstract}
This paper provides a critical examination of how digital systems within a charitable organisation in the North of England are being used to both support and challenge male perpetrators of domestic violence. While there exists a range of digital tools to support the victim-survivors of domestic violence, no tools are available to challenge the abusive and harmful behaviours of perpetrators. Through this work, we uncovered the compelling moral responsibilities intrinsic within interactions with technological systems between perpetrators and support workers. As such, we highlight four spaces of negotiation concerning a person's responsibility in changing their abusive behaviour, which we have coined as mechanisms to represent their fundamental and interconnected nature. These mechanisms include selfawareness, acknowledging the extent of harms, providing peer support and respecting authorities. These insights are the basis for offering some practical considerations for $\mathrm{HCI}$ scholars, policymakers and intervention designers in their work with perpetrators of violence.
\end{abstract}

\section{Author Keywords}

Domestic Violence; Moral Responsibility; Third Sector; Civic Technology; Violence Prevention; Social Care;

\section{CSS Concepts}

- Human-centered computing Human computer interaction (HCI) • Human-centered computing $\sim \mathrm{HCI}$ theory, concepts and models - Human-centered computing Ethnographic studies • Human-centered computing $\sim$ Empirical studies in $\mathrm{HCI}$

\section{INTRODUCTION}

The shift of responsibility between a designer and a user is a core consideration for the design, use and the resulting impact of technical tools, systems and processes. As a

\footnotetext{
(c) the authors, 2020. This is the author's version of the work. It is posted here for your personal use. Not for redistribution.

The definitive version was published as:

Rosanna Bellini, Simon Forrest, Nicole Westmarland, and Jan David Smeddinck. 2020. Mechanisms of Moral Responsibility: Rethinking Technologies for Domestic Violence Prevention Work. In Proceedings of the 2020 CHI Conference on Human Factors in Computing Systems (CHI '20), 1-13. https://doi.org/10.1145/3313831.3376693
}

popular, prominent concept, the digital design field has predominantly discussed responsibility through responsible design. An essential facet of this approach is its promotion of challenging dominant power structures and designing systems that cannot be easily misused or abused. This challenging stance can be seen through technologies to mitigate the harm users may inflict on others [39, 48, 65], or to prevent non-voluntary use of user personal data or labour by top-down, exclusionary decision-making processes [3, 41]. A complimentary, but lesser-examined approach towards the concept of responsibility within design is that of designing for responsibility: to actively consider and encourage responsible user behaviour by outlining the agency, capacity and duties of a user towards others. As the field attempts to address more significant and complex societal problems, this can lead to problems with identifying the role of - and place for - individual responsibility, particularly for individuals who have behaved irresponsibly. In line with calls for a shift from system-focused approaches to that of social, person-focused perspectives [54], we underline the importance for the field to attain clear understandings of the nature of responsibility and particularly how to address irresponsible behaviours.

The challenge of designing for responsibility is more complicated concerning issues that are politically and socially sensitive such as domestic violence [51]. Situating individual responsibility within a problem that is societal, has been misapplied to impose shame upon the victim-survivors of violence. While many works within Human-Computer Interaction have resisted this harmful tendency, it has only been relatively recently that the field has considered the role of the perpetrator responsible for inflicting this violence on others [28, 29]. The current consensus of research activity focuses on ensuring tighter security measures to prevent the irresponsible misuse of technology [5, 21, 28]. However, due to the infancy of the topic within the field, the contribution of these interventions to an overall reduction in violence is not yet clear. With an enhanced knowledge about the digitallyfacilitated harms used in domestic violence (cyber-stalking, image-based sexual abuse), there is a risk that there could be 
a more substantial expectation of means to cope and handle these abusive situations onto the victim-survivor - without addressing the perpetrator's behaviour [46]. Providing a critical view of how technology is used in interventions with perpetrators within $\mathrm{HCI}$ allows us to examine who we are holding responsible for violence and how to encourage perpetrators to behave non-violently in the future. These considerations can decisively inform approaches to supporting the prevention of current and future patterns of violence.

Within this work, we explore how technologies are being used within the context of a large, national children's charity $<$ Safe Start $>$ in the North of England, in the United Kingdom (UK). This organisation provides educational and behaviour change services to men previously or currently using violence within their intimate relationships. To define the scope of our research, we conducted a focused ethnography designed around the following research questions:

RQ1. In what ways are technologies being used to support and challenge perpetrators of domestic violence on their abusive behaviour within the context of charitable work? RQ2. How could technologies be designed within charitable work with perpetrators to support these findings?

To answer these questions, we worked with $<$ Safe Start $>$ over the space of 12 months, with data being collected by the lead author by observing and participating in their service delivery and administrative work at the charity's central Northern hub. Our findings provide an original, in-depth account of the mundane everyday technologies within the charity's practices with male perpetrators of domestic violence. As such, we demonstrate in this paper these hidden but essential moral responsibilities that a perpetrator must develop through and with technologies to desist from abusive behaviours. We have coined these spaces of negotiations in which perpetrators mediate and orientate themselves towards these responsibilities as mechanisms. As such, these mechanisms should be considered in the design of future technical and non-technical interventions: self-awareness, acknowledging the extent of harms, providing support and respecting authorities. Our paper contributes to the field of Human-Computer Interaction in the following interconnected ways: (1) we provide a critical analysis on the position of perpetrators of domestic violence within existing technical interventions; (2) we supplement these analytical findings by identifying four spaces of negotiation or 'mechanisms' for a perpetrators' responsibilities for domestic violence; and (3) we consider how those designing for perpetrators may employ these mechanisms within research, practice and policy.

\section{BACKGROUND LITERATURE}

HCI research has carefully highlighted the tension between assuming/distributing individual and collective responsibilities for (and for managing) societal harms. This extensive body of work ranges from showcasing prototype suggestions of pocket alarms [21] to the re-design of large- scale social media ecosystems [52]. However, with any shift between conceptualising individual and collective phenomena, particularly regarding safety and violence, there can be a tendency to obscure or trouble the notions of individual agency, responsibility, capacity and control. LaRose terms these situations as producing "responsibility gaps" where determining how an individual should, or could respond in the face of complexity is met with uncertainty [45]. While within this work we cannot claim to plus these gaps entirely, we do identify them and also conceptualise them as spaces where people do the work of sense-making about responsibility, and hence, we can demonstrate how this might be done. Within the following section, we provide a basis for understanding approaches and conceptualisations toward moral responsibilities within HCI research. We then examine how perpetrators are positioned within HCI work addressing domestic violence, and how this corpus might inform the design of future interventions. These findings then set the context for looking within third-sector and charitable organisations working with perpetrators of domestic violence in the UK.

\section{What Do We Mean by Responsibility?}

Responsibility, from the Latin respons- meaning 'answered' or 'offered in return' has many interpretations, generating conflation in everyday language [27, 67]. While no overarching definition of the construct exists, for this work we focus on three widely shared elements in the conceptualisation of the construct $[10,35,68]$ : (1) duty 'being responsible for'; (2) blame 'being responsible to', and (3) acting independently 'possessing responsibilities'.

Responsibility in HCI, while intentionally engaging with critical social issues has been focused predominantly on the "unforeseen consequences and reverberations of modern digital tools and services" [36]. Work within this space has examined how algorithms may reinforce existing prejudices within society [3], or how GPS technology perform a dualuse for perpetrators to further monitor their victim-survivors [28]. Scrutinising blame within software groups [2, 57], natural disasters [35] and legal cases [14] are familiar representations of what Grimpe point out as the 'consequentialist model of responsibility'. While identifying causality may be necessary, to only focus on one quality of responsibility ((2) blame) may mean we are excluding a richer consideration of responsibility's dimensions of (1) duty and (3) acting independently to technical design.

Some research has appealed to a greater critical consciousness surrounding the role of the designer and their responsibilities to scrutinise their identity, their choice of their topic area and technical design $[1,12]$. Bardzell et al. and Dombrowski et al. have produced frameworks and design considerations to make this introspective process an integral part of the research itself $[7,23]$. Baumer et al., on the other hand, look to critically examine the broader systematic context of a pre-defined 'problem' [8]. These works stand to expand the narrow, top-down approach 
towards responsibility that may equate to legal liability to an understanding of responsibility as a reflexive practice that must continually be engaged with across design. Exploring how we support individuals to take responsibility, be responsible and act independently is of vital importance for inclusive, just and secure systems.

\section{Domestic Violence, Violent Men and $\mathrm{HCl}$}

Domestic violence is an international health and social concern affecting approximately 1 in 3 women and 1 in 6 men in their lifetime, according to the World Health Organisation [30]. These estimates are subject to underreporting, while many men experience domestic violence from female perpetrators, most statistics demonstrate it is largely women and girls who experience perpetration of violence from men [13, 30, 58]. Domestic violence has been frequently addressed in $\mathrm{HCI}$ as a phenomenon without a specific responsible agent or their gender, that women and other marginalised groups must protect themselves. Jackson Katz puts a different perspective forwards by arguing that it would be a serious mistake to frame domestic violence as something that happens to victim-survivors, as this removes the agent causing such violence from view [43]. Through performing a critical scan of papers within the ACM digital library using the terms domestic violence, domestic abuse, family violence, intimate partner abuse and intimate partner violence, this section presents a state-of-the-art examination of 19 papers revealing how the agents responsible for domestic violence are positioned in technical responses to domestic violence.

Our investigation of this body of research literature demonstrated that the majority of work within the HCI discourse, at 13 out of 19 papers directly reference the abuser as an agent, or specifically relate to the victim-survivor's perpetrator. Nevertheless, despite this wealth of work, as it stands no work directly engages with and designs with men or masculinities that promote using violence in their relationships - despite there being calls to do so [4, 63, 64]. Indeed, the field has navigated the complexity of technical design through the focus on protecting and supporting victim-survivors from abusive actions, rather than directly challenging perpetrators on the unacceptability of their behaviour. This approach has included providing personal safety alarms for signalling for help [42], smartphone applications for locating information discretely online [21] and browser add-ons for wiping a victim-survivor's browser history to combat surveillance or cyberstalking [5]. In exploratory studies as to the role of technology and domestic violence in intimate relationships, Matthews et al. [52] examine the privacy and security practices of victimsurvivors experiencing abuse while Freed et al. [28] present a comprehensive list of the different technical strategies used by abusers to further their abuse. Indeed, although the agents are such abuse are present within most works, criminologist Carolyn Ramsey argues that not presenting the agents using violence on an individual basis can impede efforts to organise effective preventative methods [59]. Continuously excluding a group of relevant individuals from an approach can lead to interventions being designed based on normative, de-humanised stereotypes that are not reflective of the population group, and thereby may be ineffective. As such, in the interests of combatting further entrenched gender hierarchies, of which the field is already challenging $[1,66]$, and the reduction of violence to women, it is vital for HCI to explore engaging with perpetrators at a face-to-face level.

\section{Identifying Men as Perpetrators}

As a comprehensive analytical report by the Office of National Statistics of the UK demonstrates, the majority of perpetrators who use violence against victim-survivors do not receive appropriate interventions, arrests or sanctions in response to their abusive behaviours [58]. Although the impact of domestic violence on women, children and their relationships have been increasingly identified, Stanley et al. [69] note that effective intervention responses are far less developed. This exclusion of perpetrators is because of ignorance of the gendered nature of social work responses, 'screening out' of fathers in the social care focus, and the placement of unworkable scrutiny on victim-survivors to protect themselves and their children $[11,20,24]$. In a recent governmental review of multi-agency approaches to cases of women and children living with domestic violence, it states that there is a "distinctive lack of accountability or responsibility attributed to the perpetrator" [53]. While there have been attempts to transfer blame away from victimsurvivors, Sharron Lamb points out that "blame is not a zerosum game" [44]. By this, she highlights that the removal of blame from the target of domestic violence alone does not immediately indicate that responsibility has appropriately transferred to the perpetrator.

\section{Managing Perpetrators of Domestic Violence}

Charitable organisations, stand to be the primary, and arguably most important interface to readjust the unfair distribution of responsibility for domestic violence. Within the UK the majority of cases of domestic violence, and thereby perpetrators, are managed either through a statutory route of state Social Services Departments, Criminal Justice organisations, and Voluntary (or Community) sector organisations. These services include one to one support, counselling, behaviour change courses, helplines and creative arts practice to suit the range of economic, social and psychological needs of (frequently male) perpetrators currently using violence. Through a combination of profeminist underpinnings and Cognitive Behavioural Therapy approaches, these services understand domestic violence to be a result of largely learned behaviours (linked to the application of Bandura's Social Learning Theory [6]), behaviours that therefore can be unlearned. While the content of interventions may change depending on the provider and their theoretical background, many are designed to address similar topics. These topics include enabling men to recognise their violent behaviours and its consequences; identifying high-risk situations; tools for enhancing 
emotional self-regulation and behavioural self-control; work on empathy; reducing victim-blaming patterns; understanding the role of masculinity and gender roles; and understanding conflict and how to resolve it in a non-abusive way $[22,33,34]$. Through exercises of increasing emotional intelligence and taking responsibility for their actions, these services challenge, reinforce and support violent men to desist from using violence towards their current or exintimate relationships and family members.

\section{STUDY SETTING: <SAFE START>}

This study was performed in collaboration with $<$ Safe Start $>$, a large national children's charity (NGO) in the UK, to understand how digital technologies could play a role in assisting perpetrators to reconsider and reform their abusive behaviour. After a meeting with $<$ Safe Start $>$, the facilitators agreed for the lead author to engage with them through fieldwork of their organisational and social practices with perpetrators at a Northern charity hub 'Wild Bank'.

Wild Bank, where the lead author conducted her research study, is located in the relatively wealthy suburb of Jarrow, in Newton-on-Derwent. Despite its proximity to the city centre, the hub received a large number of service referrals for perpetrators and victim-survivors from many semi-rural surrounding districts. In 1990, in response to the emerging categorisation of domestic violence as a form of child abuse $[55,56],<$ Safe Start $>$ began to extend their services to incorporate a holistic 'family approach' to social services. Importantly this redesign of their approach specifically sought to focus on all relations and impacting factors beyond the intimate partners involved in domestic violence.

\begin{tabular}{lll}
\hline Name & Job Description & Services \\
\hline Kim & Head of Wild Bank (H) & $\begin{array}{l}\text { AADA, CRALP } \\
\text { and LPS }\end{array}$ \\
\hline Wilma & Group Coordinator (GC) & AADA \\
\hline Holly & $\begin{array}{l}\text { Junior Project Liaison Officer } \\
\text { (JPLO) }\end{array}$ & $\begin{array}{l}\text { AADA, CRALP, } \\
\text { LPS }\end{array}$ \\
\hline Laurie & Support Worker (SW) & AADA, CRALP \\
\hline Gina & Support Worker (SW) & CRALP \\
\hline Michael & Therapist, Support Worker (T-SW) & CRALP \\
\hline Service Descriptions & \\
\hline AADA & $\begin{array}{l}\text { Awareness About Domestic Abuse Programme, two-day } \\
\text { weekend course for } \leq 15 \text { men on myths, facts and realities } \\
\\
\text { about domestic violence }\end{array}$ \\
\hline CRALP & $\begin{array}{l}\text { Changing Relationships And Lives Programme, 26-week } \\
\text { behaviour change course }\end{array}$ \\
\hline LPS & $\begin{array}{l}\text { Leveraging Peer Support, eight design workshops to create } \\
\text { a peer support network for CRALP finishers }\end{array}$ \\
\hline
\end{tabular}

Table 1: Names, Job-Titles and Services of Study Participants

Given the scale of $<$ Safe Start $>$ 's national service delivery, for of this study we focused on the six team members at Wild Bank that directly coordinated and delivered services with perpetrators of domestic violence (Table 1). The scope as such covered three social services, including the awareness about domestic abuse project (AADA), the changing relationships and lives programme (CRALP) and leveraging peer support (LPS). The number of perpetrators involved in the study was approximately 62 men involved in the AADA, and 11 men involved across the CRALP and LPS, for a total of 73 male perpetrators. Relevant consent information is discussed in the following subsection.

\section{METHOD AND ANALYSIS}

Ethnographies of social care practice, particularly within the third-sector $[49,50,70]$, are becoming more numerous in HCI. This increase has been accredited to the desire to undertake research that factors out of novelty effects and reduce observation bias in observer studies. The field has as such posed ethnographic methods as an alternative to work more deeply examining the social, emotional and environmental dimensions of the human experience essential for any successful social care delivery [60]. Indeed this is in line with Corbett et al.'s essential strategy for building trust between civic actors by "meeting people where they are", where researchers must leave their workplace to engage with individuals in places more familiar to their participants [17]. We deemed a focused ethnography to be the most appropriate method to explore this topic further [71]. We believed that this subset of ethnographic methods to be most appropriate, following Wall's appeal to "make ethnography effective for new purposes" due to the lead author having pre-defined research questions (unusual in most ethnographic studies [61]) and lived experience of volunteering with domestic violence services [71]. Performing a focused ethnography ensured we could collect targeted data on field visits that were arranged in line with the $<$ Safe Start $>$ workers' frequently tight, over-worked and changeable schedules while building the essential face-toface relationships of trust with a safeguarding organisation.

In this project, we report on fieldwork conducted over the space of 12 months with Wild Bank ( $<$ Safe Start $>$ ), beginning in January 2018 and ending December 2018. The fieldwork and data collection were ethnographic, where a dedicated notebook was used to write highly detailed thick descriptions. These capture an observed event beyond surface appearances of context, detail, and social relationships and instead included the significance of voices, actions, and meanings of observations and participant behaviours [47]. Each of the activities included in the study involved bi-weekly participant observations ( 3 - 8 hours), conversations (internal and external meetings, catch-ups, informal discussions) and unstructured interviews (45 - 130 minutes) with perpetrators and support workers by the first author. These engagements were both audio-recorded and illustrated in writing through the use of thick descriptions to attempt to gather as 'raw' data as is feasible within the context setting [37]. Member-checking was also performed through quarterly presentations to the $<$ Safe Start $>$ workers on the first author's findings, 'in-situ' clarifications of the meaning of particular events within the office and participation in the analysis of this study. Ethical approval was granted by the Science and Engineering Board of the lead author's University. Perpetrators were informed that participation in the study would not impact on their case except for the disclosure of safeguarding concerns to the lead author. 
In total, the 12-month ethnography compromised of 49 independent engagements, consisting of 26 group meetings at Wild Bank, three workshops with staff and service users, four focus groups with service users, five single day-long observations and 15 observations and co-participation in service delivery (AADA, CRALP and LPS). After each visit to the field site, the lead author would transform relevant reflections into a digital field diary that was added and reflected upon post-engagement. This data collection effort resulted in approximately 1608 pages of field notes and fieldwork diaries. Audio recordings of informal interviews, observations of service users and focus groups accounted to 51 hours 37 minutes of material, of which 27 hours 10 minutes were selectively transcribed for analysis towards the work at hand. The content was selected for further analysis based on relevance, clarity, with off-topic and confidential conversations removed.

Due to our key focus on how participants made sense of their behaviours and services via thick descriptions, we selected to use a constructive-realist variation of Grounded Theory (GT) [32] through the guidance of Cupchik et al. [19] for our analysis of this work. Transcriptions were first open-coded to produce 48 qualitative codes in a shared codebook ('feeling guilty', 'reaching out'). The second stage of axial coding then produced the following categories: four spaces of practice for changing abusive behaviours that were illustrated with how specific technologies were leveraged across these concepts. Finally, during our selective coding stage, we identified there was a robust and common aspect that tied all of our categories and observed practices together: responsibility. Support workers and therapists would often demonstrate activities that identified: new, positive roles to male perpetrators (i.e. as partners, as fathers), the harm in their abusive actions and ways to behave responsibly and independently of $<$ Safe Start $>$ 's interventions.

\section{FINDINGS}

We organise our findings around the concept of mechanisms of moral responsibility: the processes in which support workers make space for and create new responsibilities for perpetrators to achieve behaviour change. We describe these practices through four manifestations of responsibility that were identified through our inductive analysis: $A$. selfawareness, B. acknowledging the extent of harms, $C$. providing peer support and D. respecting authorities. For each mechanism, we have provided our original thick descriptions from our fieldwork and show how this category was mobilised in group work with perpetrators (e.g. as in A.l. A Penny Dropping Moment; see below). In line with other presentations of ethnographies in HCI $[49,70]$ the descriptions included in this work are one of many that represent our identified categories.

We must underline here that few of the technologies listed in our findings may be considered novel for a technical audience, falling squarely into the category of mundane technologies $[40,70]$. In line with Dourish et al. stressing we have "much to learn about these technologies" that frequently go unnoticed due to their ubiquity and pervasiveness, we have sought to critically focus on familiar technologies for the novel relationships that they can produce [26]. As such, the technologies listed here are representative of the every-day management of $<$ Safe Start $>$ in reforming male perpetrators in their use of abusive behaviours.

\section{A. Self-Awareness}

Ensuring that a perpetrator of domestic violence takes responsibility (acknowledging their role in causing and accepting blame) for their abusive actions was an important first step towards behaviour change. Talking in a meeting with Laurie underlined the importance of acknowledging their part in causing their abuse:

Laurie [SW]: “... until they [perpetrators] take responsibility for the harm they've caused by genuinely looking at who they are and what they've done, then they can't work towards real change. It has to start with you."

Laurie's comment tells us two things. First, that she perceives that any behaviour change must be predicated on selfawareness, and secondly that without this process, a 'real' change in perpetrators' behaviour cannot be achieved. As such, we see Laurie determining that the perpetrator must take responsibility, and it is the service provider that then determines whether this has taken place, as one of the core differences between genuine and superficial change in a man's behaviour. The most common way in which $<$ Safe Start>'s workers sought to encourage this to happen was through the creation of social and physical spaces of selfreflection in the context of group or individual therapy which took place in on-site sessions at the hub. In these spaces, men were guided through stages of change and questioned to assess their awareness of and motivations for their violence towards others. A clear reflection on the self when dealing with abusive behaviours proved difficult for many individuals, and we witnessed both positive and negative ways to engage in self-awareness.

\section{A.1. A Penny Dropping Moment}

We observed the workers reflecting on moments where they believed technology had played a role in a perpetrator's selfrealisation that they had been abusive to their partner:

During a review session for the AADA, Holly [JPLO], Laurie [SW], Wilma $[\mathrm{GC}]$ and I were critically reflecting on the different activities used across the day. One particular activity is exploring the different facets of domestic violence through the Power and Control wheel that listed all the different tactics that abusers use to coerce and control their victims. This digital graphic was projected onto a whiteboard and Wilma reflected on the impact this had on a participant during a discussion. "You could see it, the look on his face that the penny had dropped when he read some of those tactics. I bet he was thinking 'shit I do some of those' because he started to quieten down from denying everything like he was at the start". 
Through this extract from fieldnotes, we can see how $<$ Safe Start> uses a bank of digital resources to educate and challenge the men within their service on their understanding of domestic violence. Wilma here directly assigns a moment of realisation and recognition of a man's abusive behaviours to the use of the digital projection of the Power and Control wheel [72]. Digital resources within this group session were used for self-awareness on identifying causation of abuse by comparing one's behaviour with that of the examples provided via the digital projection.

\section{A.2. Avoiding Yourself}

The time-out technique is taught within domestic violence prevention programmes as a temporary interruption technique where a perpetrator must physically remove themselves from their victim-survivor(s) for a while. It is a recommended tool, with explicit rules on what is and what is not appropriate during their time away to situations where they may have chosen to use physical violence [73].

During a therapy session with the lead care worker Kim $[\mathrm{H}]$, Max, a man who had just started a 26-week behaviour change course was recounting his previous abusive behaviour. When prompted to explain how he responded in the immediate aftermath of abusive sessions with his partner, he gave an insight as to his ritual he performed: Max: "So after, something would happen, I'd go upstairs, out the way and sit on the end of my bed, do a 'time out' ... and like, I'd scroll through my phone, scroll to look at something to ... I dunno just get away from it. You're not meant to, avoidin' yerself and that but I couldn't help it"

This account demonstrates how Max uses the mobile phone to avoid instead of enter a space in which negotiate responsibility. Max avoids contemplating his behaviour by positioning his phone as a means to escape responsibility for the situation and his behaviour. Although he is aware of violating the rules for time-out by 'avoidin' yerself', it is clear that if not carefully managed that technology can and already is providing the means to circumnavigate enforcing positive behaviours.

\section{B. Acknowledging the Extent of Harms}

As well as having to accept and be aware of their behaviours toward themselves, within all behaviour change interventions in $<$ Safe Start $>$, men are also required to consider the impact of their behaviour on others. Frequently, given that domestic violence takes place in the home (though not always [38]), 'others' typically includes the man's ex- or current partner, children and immediate family members. Within this section, we have separated the different roles within this category as the moral responsibilities to an intimate partner and as a father was regarded as notably different within $<$ Safe Start $>$.

\section{B.1. To the Victim-Survivor: Ignoring Requests}

In meetings with Kim, the lead author discussed with her how the men handle discussions regarding family members, particularly individuals whom they are not allowed to contact by court order:
$\operatorname{Kim}[\mathbf{H}]$ : "It's tough because the men frequently go from being undeniably abusive partners and fathers, but partners and fathers all the same, to being ... well, cut off from those roles. No calling for a chat, texting a reminder to pick the kids up, messaging support, sharing a funny photo absolutely nothing with technology."

Kim listed several ways in which the relationships the men once had before the domestic abuse had been identified had been 'cut off' for the further protection of victim-survivors. While she made clear to the lead author following this vignette that she is not criticising this approach, her account does tell us that she acknowledges that digital communication expected between partners and the duties this provided are no longer accessible to the perpetrator. This frequently meant attempting not to re-traumatise their victimsurvivor by reducing face-to-face and digital contact. In a later fieldwork session a perpetrator Sandeep goes into more detail about this rejection of technology:

Sandeep: "So she [victim-survivor] sent me a friend request on Facebook, wanting to reconnect like we always do on a Sunday afternoon after the separation ... it would have been a good opportunity to talk things through with her, but it's not worth putting her through that again. It was painful, ignoring the person you've spent the last ten years of your life with, but I didn't want to hurt her again so I ignored the request."

This example illustrates Sandeep's awareness of how his responsibilities to his now ex-partner have now changed through digital means; going from arranging a meeting ("like we always do") to acknowledge the potential of this process now causing pain ("I didn't want to hurt her"). Technology here reinforces those duties that Sandeep now has towards not causing harm but also problematises this as a reminder of the duties as a partner he once had towards her.

\section{B.2. To the Child(ren): Considering New Perspectives}

It was infrequent within $<$ Safe Start $>$ services for a series of incidents of domestic violence to only include a single victim-survivor. Group facilitators stressed that children within the family were not just passive witnesses of abuse, but were actively harmed as a result of the man's actions towards his partner, and sometimes themselves physically. To ensure children were appropriately represented within the session, $<$ Safe Start $>$ courses frequently used the method of perspective-taking, to view a situation from the perspective of another person affected by violence, to encourage building empathy and emotional understanding. This technique was regarded by all staff members as a good way to remind the men of their past, present and future responsibilities for their behaviour as a partner, a father, a family member and a responsible person. Keith's (a perpetrator's) discussion of the activity of typing a message from another person on his behaviour reminded him of how his abusive actions had an impact on his daughter: 
Keith: "When I was typing out that letter on the computer in the library, from what me daughter would want to send to me if she could, I just ... lost it, it's truly the hardest thing I've done in my life ... knowin' I've done that much damage. Typing that has really made me consider how many dads would be typing that..."

Here, Keith imagines a normative responsibility or duty of what fathers should be to their children and uses this to compare with his actions ("I've done that much damage"). In this way, we can see how the use of a simple word document and a basic task of letter writing had a profound impact on Keith to reconsider his role as a father in comparison to other fathers ("how many dads would be typing that").

\section{Providing Peer Support}

Unless specified otherwise, for reasons such as extreme anxiety or language barriers, men were encouraged to take part in weekly group therapy interventions consisting of around eight to ten men. As many of $<$ Safe Start $>$ behaviour change courses are discussion-based, this provided a space for men to disclose their own experience of violence, and form positive bonds of friendship with other service users within the charity. In this section, we focus specifically on how < Safe Start> and the men they worked with used technology to enforce a positive focus on responsibilities towards change and challenge negative avoidances of responsibility through peer support and mentorship.

\section{C.1. All Coming Together}

This encouragement of peers sharing support required much encouragement and careful activity design by facilitators as therapist Michael shares in the vignette below:

Following a very highly attended design workshop, the lead author approached one of the co-facilitators to examine the causation for the high numbers. After thinking for a while, Michael [T-SW] responded "... our role as therapists is, is to not only get them to be responsible and honest to us but to be responsible and honest to each other through sharing experiences ... as we design activities for them that have meaning and use beyond the [behaviour change] session. The shared playlist activity where they're each tasked with selecting a song that represents their journey is one of those, and the men can listen to it whenever, wherever they want for when they've slipped, or for when they want to remind themselves of how far they've all come together".

Here we can see that the facilitators have identified the importance of developing group activities, in this case, the curation of digital content that directly involves each member of the group ("each ... selecting a song"). Within this task, not only is contributing to the activity important but also what the playlist is understood to be after the behaviour change course is finished. Michael underlines that the use of the shared playlist is for both the reinforcement of positive behaviours in case of "when they've slipped", and also a reminder of their responsibility to independently reflect on reformation of abusive to non-abusive behaviours. At a later session, Gary confirmed this during a follow-up session:

Gary: I'm on the road a lot so I stick it on when I'm feeling low about myself and my history. Since I got the others on Spotify it's a bit funny as I can see who's been listening to it recently, so I can see them taking what we've done together seriously.

Gary's actions outline how something as simple as a playlist can not only combat his feelings of low mood but also allow him to check the actions of the others post-course ("can see them taking [the programme] seriously"). Whether the other men know this or not means that Gary has placed himself in a position where he behaves responsibly in realising, he needs to listen to the playlist. This account also shows he is also judging the other members of the groups' attitude to taking "what we've done together seriously" by judging whether others are also behaving responsibly.

\section{C.2. Assuming Responsibility for Other Men}

This position of responsibility that men would take on concerning other men would also take on other forms, as perpetrator Dario illustrates in talking about the attendance of another man at the group:

Dario: 'I kner Ben struggles wit' gettin' up sometimes to come to group, so after our first meet he ask'd me to start Whatsapp'n him encouragement to attend. 'course I'm happy to since he's not gonna change if he isn't here"

This example illustrates how for Ben, one motivation for change is channelled through entrusting Dario with the responsibility to instant message him for encouragement for attendance (or berate him for non-attendance) at group therapy. In this situation, Dario welcomes this new duty as he expresses that he understands that without this digital practice Ben is not "gonna change" his abusive behaviour if not partaking within the sessions as a group. Within this description, we can see that Ben understands that his methods of ensuring responsibility to himself alone are not enough as these alone are something that he 'struggles' with managing. Instead, Ben has passed the responsibility and duty of ensuring he attends to Dario and thus makes himself responsible to another member of the group through instant messaging. From this account, we can assume that without the role of communicative technologies between these two men that Ben's attendance may have been impacted without this important duty and relationship.

\section{Respecting Authority}

The majority of men within this study were referred to $<$ Safe Start> social services through external organisations such as police and children's social care. As such, although some men had voluntarily enrolled in a course, many already had a negative predisposition towards being challenged on their behaviour. Facilitators in $<$ Safe Start $>$ frequently expressed what Holly described as a "delicate balancing act" of validating an external organisations judgement of identifying 
domestically violent behaviours, but also making space for non-judgement within their organisation.

\section{D.1. Doing the Work}

During a group introduction where the AADA team (Holly, Wilma, Laurie and Kim), the staff members elaborated on how building up relationships of trust and reliability were constructed across the course. This was done by setting the men tasks for self-reflection and encouraging them to contribute personal reflections to both the facilitators and other men partaking in the group:

Wilma [GC] explained that all behaviour change courses within $<$ Safe Start $>$ set individual work in the form of what the organisation termed 'homework'. "It's videos and activities to reflect on themselves before the next session, and they deliberately get you to share something about yourself that you wouldn't normally do. That builds the bridge between them and us". When I ask how the facilitators ensure the men complete their homework Wilma chuckled and responded "We can tell when they haven't done it because when we ask them to share, they go all sheepish and quiet. [I] Can tell you, they don't forget to do it next time!"

We can see here that building responsibility and trust between a facilitator and a perpetrator takes place through the completion of 'homework' which consists of online activities and videos. Wilma underlines that the men might foster a sense of responsibility to complete this homework as they are then asked to share this completed work. While Wilma goes short of shaming the men for not completing the work, she does state that from feeling "sheepish" that this is enough to encourage them to do it for next time.

\section{D.2. Breaking Trust}

Being concerned about upsetting or disappointing the facilitators whom the perpetrators had built a trust with was a core concern for each individual involved in group work. Tommy, a man who had recently completed a behaviour change course, captured this sentiment when the lead author asked about his motivations for longitudinal change:

Tommy: "'sal reet me sayin' that I'll change, but if Gina $[\mathrm{SW}]$ or Kim $[\mathrm{H}]$ get a phone call or an email from the police sayin' I've done something again ... well they just won't trust me again, and I don't want that so I'm gonna ensure it doesn't happen"

Kim $[\mathrm{H}]$ : “it's not just about catching you doing it [violence], it's more than just an email or call though Tommy as the police can't detect everything.

Tommy's dedication to "ensuring it [violence] doesn't happen again" is held up directly by the concern of the loss of trust between himself and his care worker Kim. In this way, the role of a phone call or an email from an external organisation directly disrupts the appearance of Tommy's reformation of his negative behaviours. As such, here Tommy behaves in what he feels is a responsible manner to avoid external organisations such as the police violating this relationship of trust that he has formed with $<$ Safe Start $>$. This concern for matching that someone states what change they have made ("sayin' I'll change") and what they do ("sayin' I've done something again") is further explored by Kim's statement. In her response to Tommy's statement, she reminds him that this violation of trust can occur beyond a call or an email ("it's not just about catching you"), and it was not enough to be responsible to external organisations.

\section{DISCUSSION}

These findings demonstrate how perpetrators and charities mobilise technology in their efforts to reform domestically abusive behaviours. While prior studies have identified technology solely as a catalyst to further abuse [46, 52], we realised that by not understanding the role of responsibility both with and without technology in this context could inadvertently cause harm in subtler ways. As we noted earlier, to remove responsibility for domestic violence from societal factors does not necessarily equate to an assumption of responsibility by individuals [44]. It was only through our work that we identified that $<$ Safe Start $>$ were well aware of this dilemma through engaging with perpetrators and actively designed all their digital practices to challenge this with their service users. From assigning homework to continuously work on self-reflection to creating activities than generate organic networks of support, there was a continuous return to focus on the perpetrator and their behaviour. In this way, we discovered that responsibility in this context was less about describing what gaps exist, or assigning blame, and more about identifying further ways to navigating these complexities of sometimes contradicting and unclear responsibilities to violence prevention. Within this next section, we identify practical steps that designers and researchers interested in participatory design, harm prevention and behaviour change can take to make our findings actionable. We first identify two conceptual considerations for the use of mechanisms in the design of future technologies and three practical considerations for researchers to work more closely with the third-sector and perpetrators.

\section{Understanding Responsibilities as Moral Mechanisms}

Designing digital interventions that do not directly address the cause of violence - the perpetrator - does not only exclude responsible agents from the picture but obscures the important spaces of behaviour change that third-sector workers are already addressing. Based on the meaningful interactions between users and technology that we identified in our study, we have two conceptual recommendations for how researchers and designers can orientate themselves towards responsibility in interventions; (1) Designing for Responsibility and (2) Mitigating Domestic Violence as Changing Behaviour.

\section{Designing for Responsibility}

Understanding responsibility for abusive behaviour is not a static, discrete event that occurs to a perpetrator in the same way as the single act of assigning blame [44, 68]. Instead, we identified responsibility as a process of re-negotiation, self- 
realisation and adoption of new duties over time, normally with professional intervention. Just as responsible design tries to design systems that cannot be easily misused or abused, within this space, we also have to see designing for responsibility as an independent aspect of system design to see how technology might be leveraged to encourage the development of non-abusive behaviours. In this way, our findings of spaces of negotiation in the form of mechanisms question conventional approaches in responsible design in technology, where most discussions of responsibility are positioned at a top-down level from a perspective of criminal justice; one that is punitive and hierarchical [25, 62]. Although rejecting a request of a victim-survivor on Facebook could, in some cases, be abusive, for Sandeep it was a way of demonstrating responsible behaviour in acknowledging the harms he could cause his partner. Just as technology can be used as a channel of abuse, it can also be acknowledged as a key space to enact responsibilities (" $n o$ calling for a chat ... absolutely nothing with technology"). As such, we recommend that designers and practitioners consider what responsible behaviours they wish to encourage through technical designs, alongside designing to mitigate potential misuse.

\section{Mitigating Domestic Violence as Changing Behaviour}

Responsibility for the harms caused by perpetrators featured consistently across many aspects of our thick descriptions with $<$ Safe Start $>$ and is a core 'moment of realisation' for many of our service users in this work. While there can be a desire to focus on understanding the "consequences and reverberations" of abuse [36], we note that this is just one of the four mechanisms we identified across our study. Abusive individuals demonstrate abusive behaviours that need to be challenged, reformed and supported across an identifiably difficult process, for the perpetrator, the victim-survivor(s) and professionals involved. Through what Corbett et al. described as "meeting people where they are" [17], we took this recommendation to mean not only meeting civic actors such as $<$ Safe Start $>$ physically in their workplace ('Wild Bank') but also meeting the service users 'where they are' mentally on their journey for change. This does not mean to squarely excuse domestic violence as responsibility for the individual to resolve, but rather consider how we as designers can support attempts to challenge and change abusive behaviours as they occur. In the same way that Clarke et al. and Matthews et al. provide victim-survivors with the personhood to express their agency through technology [15, 52], so should responsibility for the reformation of an individual's behaviours be situated on the cause of such violence. We as such would recommend designers when approaching domestic violence to also consider it as a matter of changing behaviour, alongside efforts on designing for security and privacy.

\section{Beyond 'Perpetrator' or 'Abuser'}

When perpetrators are excluded from the intervention or viewed by their violent actions alone, it appears implausible to consider how these agents could be designed for without generating misunderstandings, the potential for misuse, or even further harm. While men who use violence in relationships are recognised to manipulate reporting events on reality (as we discovered through our vignettes), in line with our prior discussion, we cannot use this fact as an excuse to not engage with this group for design [44]. In this section, we identify three practical steps that we found to be useful considerations for future work with perpetrators and for the context of the third-sector: (1) Starting from the Bottom-Up; (2) Embrace and Account for the Mundane and (3) Anticipate Temporal Influences.

\section{Starting from the Bottom-Up}

Taking an in-depth, detailed look at how behaviour change was performed within a sensitive setting allowed us to identify pathways of change and negotiation for perpetrators. In many ways, we believe our findings contribute to the growing bodies of work that aspires to provide an alternative perspective to designing for wider societal problems by reaffirming individual agency and capacity for change $[8,23$, 36]. These capacities for changing abusive behaviours can only be immediately identified at the personal, individual level which has frequently been (understandably [44]) avoided in domestic violence prevention. The mechanism of Self-Awareness in particular we note has a strong orientation towards examining the self before moving onto responsibilities that involve others (such as Acknowledging the Extent of Harms). As Laurie discussed in A. SelfAwareness, the process of the men "looking at who they are" and "what they've done" was an essential first step towards behaviour change. When given an opportunity, some men did, after learning of their responsibilities towards others, use this space of negotiation appropriately, such as Gary's selfappointment as an encourager for other men (C.1. All Coming Together) and Sandeep's self-reflection on his behaviours (B.1. To the Victim-Survivor: Ignoring Requests). In this way, we recommend that researchers start with the individual perpetrator before expanding to examine how these might intersect with other agents in the domestic violence eco-system. We believe this provides an immediate, tangible and solid grounding for design moving forward.

\section{Embrace and Account for the Mundane}

The novelty of the technologies that we witnessed within this study did, perhaps surprisingly, not venture beyond that of a smartphone (to scroll through) or a WhatsApp social media group - arguably resulting in descriptions of mundane technologies [26]. Although we focused our attention on a detailed look into a single-third sector organisation, we believe that based on the corpus of other work on this topic $[16,49]$, our study does represent an accurate picture of the practices involved by a technically-illiterate and resourcepoor third-sector context in the context of UK austerity. We do not believe that the lack of or use of simplistic technologies is something to deter motivated designers, however, as Strohmayer et al. writes "small changes to the materiality of mundane technologies" can generate an enormously positive impact to those reliant on those 
technologies, particularly those groups excluded from mainstream design [70]. We can foresee that a small addition of a digital reminder for Max to perform his 'time-out' correctly with instructions or nudge him before a 'time-out' is necessary could have had a more constructive influence over his behaviour. While a reminder may not be novel or even modern technology, we recommend that designers and researchers take a full inventory of what technologies charities are already using with perpetrators and their subsequent functionality to identify areas of improvement.

\section{Anticipate Temporal Influences}

This focused ethnography spanned over 12 months which entailed that we were able to observe many perpetrators at different stages on their behaviour change towards nonviolence. Within this time our participants ranged from avoidant behaviours with technology at the start of their journey (such as deliberately misusing a time-out) to the adoption of a positive, guardian role through a WhatsApp group for other men (acting as a peer). The creation of spaces of social and physical spaces for therapy as we note in our thick descriptions took time and patience on behalf of the support workers to develop. While we would be hesitant to impose an arbitrary length of time to any future study, it was only through the lead researcher's ability to 'build a bridge' through time and trust that the participants felt comfortable expressing sensitive disclosures that many perpetrators found shameful [18]. In this way, we would recommend that both for the benefit of service users and the resource-poor thirdsector that researchers seriously consider a longitudinal approach towards data collection or an intensively focused ethnography to capture the range of different responsibilities that can become apparent across a length of time.

\section{Critical Reflection and Limitations}

Because of its nature, domestic violence breaks trust, inflicts harm, and disrupts organic relationships surrounding a perpetrator $[15,51]$. In some cases, connections are justifiably and irrevocably broken, and it is unethical and dangerous to insist on rebuilding these out of concern for retraumatising victim-survivors. As such, we would be wary for designers to see our work as justification to understand responsibility mechanisms as a way to forge new relationships without care. However, there remains a great power in the process of noting existing practical mobilisations, relationships and interactions with technology, which inevitably formed how our mechanisms took shape. We do so to methodologically extend rich qualitative approaches so that they might better inform the design of future work within $\mathrm{HCI}$ and technical studies.

Our process for this work was deliberately in-depth to inform a better understanding of the role of technologies and what role they played within this space. As we did not focus our data collection on non-technical tools in this context, we regrettably cannot contrast the impact of a change in service material or the absence of technology with a robust evidencebase. Indeed, this process required a lengthy and emotionally intensive investment of trust, time and resource for both the lead author and $<$ Safe Start $>$, which some organisations would not be able to offer so readily $[9,16]$. As such, we recommend researchers consider an engaged approach that seeks to involve both front-line and managerial staff handling perpetrators of domestic violence [29]. In particular qualitative methods such as diary studies can appropriate the rich, contextual detail of focused ethnography without the researcher being required to be present. Additionally, we speculate that cultural probes and their ability to "discover the unknown" [31] or underrepresented may provide participants with the responsibility of what they wish to share presents a stimulating meta dimension to future explorations of responsibility in design.

\section{CONCLUSION AND FUTURE WORK}

Domestic violence is a global, serious problem that requires sensitive, considered and effective responses to mitigate the harm it causes. While the field of HCI has begun to explore the role of technology concerning victim-survivors, through our study, we specifically examined the role of technology within a charitable organisation in their efforts to encourage male perpetrators to desist from their abusive behaviours. Within this work, we report on how mundane technologies were being purposed to support instilling morally responsible behaviours and encouraging male perpetrators to take responsibility for the harm their actions had caused through four interlocking mechanisms: Self-Awareness, Acknowledging the Extent of Harms, Providing Peer Support and Respecting Authorities. We conclude with some practical considerations which we invite the community to take into account for future design work of long-term prevention strategies targeting domestic violence.

In future work, we intend to explore how these identified mechanisms of responsibility within digital tools can be leveraged within existing service delivery. In particular, we are especially interested in exploring how a peer support network can be designed - and possibly improved through technology use - to safely facilitate support perpetrators in their journey through changing behaviours.

\section{ACKNOWLEDGEMENTS}

We would like to thank all of our participants, our partners and our reviewers for their contribution to, and their on-going support in this research study. This research was funded through the EPSRC Centre for Doctoral Training in Digital Civics (EP/L016176/1). Data supporting this publication is not openly available due to confidentiality considerations. Access may be possible under appropriate agreement. Additional metadata record at http://dx.doi.org/10.25405/data.ncl.11522472

\section{REFERENCES}

[1] Ahmed, A.A. 2018. Trans Competent Interaction Design: A Qualitative Study on Voice, Identity, and Technology. Interacting with Computers. 30, 1 (Jan. 2018), 53-71. DOI:https://doi.org/10.1093/iwc/iwx018. 
[2] Alechina, N. et al. 2017. Causality, Responsibility and Blame in Team Plans. Proceedings of the 16th Conference on Autonomous Agents and MultiAgent Systems (Richland, SC, 2017), 1091-1099.

[3] Alkhatib, A. and Bernstein, M. 2019. Street-Level Algorithms: A Theory at the Gaps Between Policy and Decisions. Proceedings of the 2019 CHI Conference on Human Factors in Computing Systems - CHI '19 (Glasgow, Scotland Uk, 2019), 1-13.

[4] Anderson, K.L. and Umberson, D. 2001. Gendering Violence: Masculinity and Power in Men's Accounts of Domestic Violence. Gender and Society. 15, 3 (2001), 358-380.

[5] Arief, B. et al. 2014. Sensible Privacy: How We Can Protect Domestic Violence Survivors Without Facilitating Misuse. Proceedings of the 13th Workshop on Privacy in the Electronic Society (New York, NY, USA, 2014), 201-204.

[6] Bandura, A. 1971. Social Learning Theory. General Learning Corporation.

[7] Bardzell, S. 2010. Feminist HCI: Taking Stock and Outlining an Agenda for Design. Proceedings of the SIGCHI Conference on Human Factors in Computing Systems (New York, NY, USA, 2010), 1301-1310.

[8] Baumer, E.P.S. and Silberman, M.S. 2011. When the Implication is Not to Design (Technology). Proceedings of the SIGCHI Conference on Human Factors in Computing Systems (New York, NY, USA, 2011), 2271-2274.

[9] Bellini, R. et al. 2019. Vocalising Violence: Using Violent Mens' Voices for Service Delivery and Feedback. Proceedings of the 9th International Conference on Communities \& Technologies Transforming Communities (New York, NY, USA, 2019), 210-217.

[10] Birnbacher, D. 2009. Responsibility for Future Genenerations - Scope and Limits. Studia Ecologiae et Bioethicae. 1 (2009), 75-106.

[11] Brown, L. et al. 2009. Manufacturing ghost fathers: the paradox of father presence and absence in child welfare. Child \& Family Social Work. 14, 1 (Feb. 2009), 25-34. DOI:https://doi.org/10.1111/j.1365-2206.2008.00578.x.

[12] Brulé, E. and Spiel, K. 2019. Negotiating Gender and Disability Identities in Participatory Design. Proceedings of the 9th International Conference on Communities \& Technologies - Transforming Communities (New York, NY, USA, 2019), 218-227.

[13] Centre for Disease Control and Prevention 2010. National Intimate Partner and Sexual Violence Survey.

[14] Chockler, H. et al. 2015. Causal Analysis for Attributing Responsibility in Legal Cases. Proceedings of the 15th International Conference on Artificial Intelligence and Law (New York, NY, USA, 2015), $33-42$.

[15] Clarke, R. et al. 2012. Sharing Narrative and Experience: Digital Stories and Portraits at a Women's Centre. CHI '12 Extended Abstracts on Human Factors in Computing Systems (New York, NY, USA, 2012), 1505-1510.

[16] Clarke, R.E. et al. 2019. Socio-materiality of trust: codesign with a resource limited community organisation. CoDesign. 0, 0 (Jul. 2019), 1-20. DOI:https://doi.org/10.1080/15710882.2019.1631349.

[17] Corbett, E. and Le Dantec, C.A. 2018. Exploring Trust in Digital Civics. Proceedings of the 2018 Designing Interactive Systems Conference (New York, NY, USA, 2018), 9-20.

[18] Corbett, E. and Le Dantec, C.A. 2018. Going the Distance: Trust Work for Citizen Participation. Proceedings of the 2018 CHI Conference on Human Factors in Computing Systems (New York, NY, USA, 2018), 312:1-312:13.

[19] Cupchik, G. 2001. Constructivist Realism: An Ontology That Encompasses Positivist and Constructivist Approaches to the Social Sciences. Forum Qualitative Sozialforschung / Forum: Qualitative Social Research. 2, 1 (Feb. 2001). DOI:https://doi.org/10.17169/fqs-2.1.968.

[20] Devaney, J. 2009. Children's Exposure to Domestic Violence: Holding Men to Account. The Political Quarterly. 80, 4 (Dec. 2009), 569-574. DOI:https://doi.org/10.1111/j.1467923X.2009.02050.x.

[21] Dieterle, B. 2015. Designing Smartphone Apps for at Risk Populations: Domestic Violence Survivors and User Experience. Proceedings of the 33rd Annual International Conference on the Design of Communication (New York, NY, USA, 2015), 14:114:2.

[22] Dixon, L. et al. 2012. Perpetrator programmes for partner violence: Are they based on ideology or evidence? Legal and Criminological Psychology. 17, 2 (Sep. 2012), 196-215. DOI:https://doi.org/10.1111/j.2044-8333.2011.02029.x.

[23] Dombrowski, L. et al. 2016. Social Justice-Oriented Interaction Design: Outlining Key Design Strategies and Commitments. Proceedings of the 2016 ACM Conference on Designing Interactive Systems (New York, NY, USA, 2016), 656-671.

[24] Douglas, H. and Walsh, T. 2010. Mothers, Domestic Violence, and Child Protection. Violence Against Women. 16, 5 (May 2010), 489-508. DOI:https://doi.org/10.1177/1077801210365887. 
[25] Dourish, P. 2010. HCI and Environmental Sustainability: The Politics of Design and the Design of Politics. Proceedings of the 8th ACM Conference on Designing Interactive Systems (New York, NY, USA, 2010), 1-10.

[26] Dourish, P. et al. 2010. Theme Issue on Social Interaction and Mundane Technologies. Personal Ubiquitous Comput. 14, 3 (Apr. 2010), 171-180. DOI:https://doi.org/10.1007/s00779-010-0281-0.

[27] Fincham, F.D. and Jaspars, J.M. 1980. Attribution of Responsibility: From Man the Scientist to Man As Lawyer. Advances in Experimental Social Psychology. L. Berkowitz, ed. Academic Press. 81-138.

[28] Freed, D. et al. 2018. “A Stalker's Paradise”: How Intimate Partner Abusers Exploit Technology. Proceedings of the 2018 CHI Conference on Human Factors in Computing Systems (New York, NY, USA, 2018), 667:1-667:13.

[29] Freed, D. et al. 2017. Digital Technologies and Intimate Partner Violence: A Qualitative Analysis with Multiple Stakeholders. Proc. ACM Hum.-Comput. Interact. 1, CSCW (Dec. 2017), 46:1-46:22. DOI:https://doi.org/10.1145/3134681.

[30] García-Moreno, C. and World Health Organization 2005. WHO multi-country study on women's health and domestic violence against women: initial results on prevalence, health outcomes and women's responses. WHO.

[31] Gaver, B. et al. 1999. Design: Cultural Probes. Interactions. 6, 1 (Jan. 1999), 21-29. DOI:https://doi.org/10.1145/291224.291235.

[32] Glaser, B.G. 1965. The Constant Comparative Method of Qualitative Analysis. Social Problems. 12, 4 (1965), 436-445. DOI:https://doi.org/10.2307/798843.

[33] Gondolf, E. 2002. Batterer Intervention Systems: Issues, Outcomes, and Recommendations.

[34] Gondolf, E.W. 2004. Evaluating batterer counseling programs: A difficult task showing some effects and implications. Aggression and Violent Behavior. 9, 6 (Sep. 2004), 605-631.

DOI:https://doi.org/10.1016/j.avb.2003.06.001.

[35] Gotterbarn, D. 2001. Informatics and professional responsibility. Science and Engineering Ethics. 7, 2 (Jun. 2001), 221-230. DOI:https://doi.org/10.1007/s11948-001-0043-5.

[36] Grimpe, B. et al. 2014. Towards a Closer Dialogue Between Policy and Practice: Responsible Design in HCI. Proceedings of the SIGCHI Conference on Human Factors in Computing Systems (New York, NY, USA, 2014), 2965-2974.
[37] Hammersley, M. 2018. Routledge Revivals: What's Wrong With Ethnography? (1992) : Methodological Explorations. Routledge.

[38] Hattery, A. 2009. Intimate Partner Violence. Rowman \& Littlefield.

[39] Havron, S. et al. 2019. Clinical Computer Security for Victims of Intimate Partner Violence. (2019), 105-122.

[40] Hillman, D. and Gibbs, D. 1999. Century Makers: One Hundred Clever Things We Take for Granted Which Have Changed Our Lives over the Last One Hundred Years. Welcome Rain.

[41] Irani, L.C. and Silberman, M.S. 2013. Turkopticon: Interrupting Worker Invisibility in Amazon Mechanical Turk. Proceedings of the SIGCHI Conference on Human Factors in Computing Systems (New York, NY, USA, 2013), 611-620.

[42] Jordán Conde, Z. et al. 2008. GuardDV: A Proximity Detection Device for Homeless Survivors of Domestic Violence. CHI '08 Extended Abstracts on Human Factors in Computing Systems (New York, NY, USA, 2008), 3855-3860.

[43] Katz, J. 2012. Violence against women -- it's a men's issue.

[44] Lamb, S. 1999. The Trouble with Blame: Victims, Perpetrators, and Responsibility. Harvard University Press.

[45] LaRose, R. et al. 2008. Promoting Personal Responsibility for Internet Safety. Commun. ACM. 51, 3 (Mar. 2008), 71-76. DOI:https://doi.org/10.1145/1325555.1325569.

[46] Leitão, R. 2018. Digital Technologies and Their Role in Intimate Partner Violence. Extended Abstracts of the 2018 CHI Conference on Human Factors in Computing Systems (New York, NY, USA, 2018), SRC11:1SRC11:6.

[47] Lincoln and Denzin 2004. Turning Points In Qualitative Research: Tying Knots in a Handkerchief. AltaMira Press.

[48] Mahar, K. et al. 2018. Squadbox: A Tool to Combat Email Harassment Using Friendsourced Moderation. Proceedings of the 2018 CHI Conference on Human Factors in Computing Systems (New York, NY, USA, 2018), 586:1-586:13.

[49] Marshall, M. et al. 2018. Accountability Work: Examining the Values, Technologies and Work Practices That Facilitate Transparency in Charities. Proceedings of the 2018 CHI Conference on Human Factors in Computing Systems (New York, NY, USA, 2018), 275:1-275:12. 
[50] Marshall, M. et al. 2016. Accountable: Exploring the Inadequacies of Transparent Financial Practice in the Non-Profit Sector. Proceedings of the 2016 CHI Conference on Human Factors in Computing Systems (New York, NY, USA, 2016), 1620-1631.

[51] Massimi, M. et al. 2012. Finding a New Normal: The Role of Technology in Life Disruptions. Proceedings of the ACM 2012 Conference on Computer Supported Cooperative Work (New York, NY, USA, 2012), 719728.

[52] Matthews, T. et al. 2017. Stories from Survivors: Privacy \& Security Practices when Coping with Intimate Partner Abuse. Proceedings of the 2017 CHI Conference on Human Factors in Computing Systems (New York, NY, USA, 2017), 2189-2201.

[53] McBride, E. 2018. The multi-agency response to children living with domestic abuse. Probation Journal. 65, 1 (Mar. 2018), 99-100. DOI:https://doi.org/10.1177/0264550517752751a.

[54] McCarthy, J. and Wright, P. 2007. Technology as Experience. MIT Press.

[55] Mullender, A. 1996. Children Living with Domestic Violence. Adoption \& Fostering. 20, 1 (Apr. 1996), 815. DOI:https://doi.org/10.1177/030857599602000104.

[56] Mullender, A. et al. 2002. Children's Perspectives on Domestic Violence. SAGE.

[57] Norman, T.J. and Reed, C. 2002. Group Delegation and Responsibility. Proceedings of the First International Joint Conference on Autonomous Agents and Multiagent Systems: Part 1 (New York, NY, USA, 2002), 491-498.

[58] Office for National Statistics 2018. Domestic abuse in England and Wales: year ending March 2018. Home Office.

[59] Ramsey, C.B. 2015. The Stereotyped Offender: Domestic Violence and the Failure of Intervention. Penn State Law Review. 120, (2016 2015), 337-420.

[60] Reid, J. et al. 2011. A Research Methodology for Evaluating Location Aware Experiences. Personal Ubiquitous Comput. 15, 1 (Jan. 2011), 53-60. DOI:https://doi.org/10.1007/s00779-010-0308-6.

[61] Roper, J.M. and Shapira, J. 2000. Ethnography in Nursing Research. SAGE.

[62] Rosenberg, R.S. 1998. Beyond the Code of Ethics: The Responsibility of Professional Societies. Proceedings of the Ethics and Social Impact Component on Shaping
Policy in the Information Age (New York, NY, USA, 1998), 18-25.

[63] SafeLives 2019. Tech vs Abuse: Research Findings 2019.

[64] Salter, M. 2016. 'Real men don't hit women': Constructing masculinity in the prevention of violence against women. Australian \& New Zealand Journal of Criminology. 49, 4 (Dec. 2016), 463-479. DOI:https://doi.org/10.1177/0004865815587031.

[65] Seering, J. et al. 2019. Designing User Interface Elements to Improve the Quality and Civility of Discourse in Online Commenting Behaviors. Proceedings of the 2019 CHI Conference on Human Factors in Computing Systems (New York, NY, USA, 2019), 606:1-606:14.

[66] Segrave, M. and Vitis, L. 2017. Gender, Technology and Violence. Routledge.

[67] Shaver, K. 1985. The Attribution of Blame: Causality, Responsibility, and Blameworthiness. Springer-Verlag.

[68] Shaver, K.G. 2012. The Attribution of Blame: Causality, Responsibility, and Blameworthiness. Springer Science \& Business Media.

[69] Stanley, N. et al. 2011. Children's Experiences of Domestic Violence: Developing an Integrated Response From Police and Child Protection Services. Journal of Interpersonal Violence. 26, 12 (Aug. 2011), 23722391. DOI:https://doi.org/10.1177/0886260510383030.

[70] Strohmayer, A. et al. 2017. Technologies and Social Justice Outcomes in Sex Work Charities: Fighting Stigma, Saving Lives. Proceedings of the 2017 CHI Conference on Human Factors in Computing Systems (New York, NY, USA, 2017), 3352-3364.

[71] Wall, S.S. 2014. Focused Ethnography: A Methodological Adaptation for Social Research in Emerging Contexts. Forum Qualitative Sozialforschung /Forum: Qualitative Social Research. 16, 1 (Nov. 2014). DOI:https://doi.org/10.17169/fqs-16.1.2182.

[72] Wheels: https://www.theduluthmodel.org/wheels/. Accessed: 2019-08-12.

[73] Wistow, R. et al. 2017. "Time Out": A Strategy for Reducing Men's Violence Against Women in Relationships? Violence Against Women. 23, 6 (May 2017), 730-748. DOI:https://doi.org/10.1177/1077801216647944. 